\title{
RELAÇÕES E INTERAÇÕES NA CULTURA ARQUITETÔNICA E URBANÍSTICA
}

\author{
Mônica Junqueira de Camargo
}

A arquitetura brasileira vive um momento de euforia na demanda de trabalhos, como há muito não se via. Os escritórios estão abarrotados de projetos, procurando desesperadamente por jovens profissionais e terceirizando boa parte de seus detalhamentos. Situação essa que seria invejável se a qualidade dos projetos acompanhasse, na mesma relação, a quantidade das solicitações, cuja avaliação não nos arriscamos a fazer sem um cuidadoso estudo. Ainda assim, em uma visão panorâmica, apenas com base em uma observação empírica, mesmo reconhecendo a excelência de alguns projetos, não se identifica nenhuma revolução à vista, sobretudo para a solução dos tradicionais problemas urbanos. Mais uma vez podemos estar desperdiçando oportunidades de construção de ações coletivas, ainda que a partir de trabalhos individuais. Tal constatação nos leva a indagar sobre as possíveis relações entre as pesquisas científicas e o desenvolvimento real da arquitetura.

O conteúdo desta edição é indicador do interesse dos pesquisadores contemporâneos à investigação dos fenômenos arquitetônicos enquanto processos, seja no âmbito da criação, seja da história ou da tecnologia, reconhecendo a arquitetura como fato cultural, para o qual pode ser menos relevante as origens das manifestações do que suas coexistências e seus desdobramentos em determinados contextos. Portanto, as relações entre idéias, situações e condições da arquitetura que dominam os temas dos artigos publicados nesta edição, denotam o desafio dos pesquisadores para enfrentar a complexidade da cultura arquitetônica, investigando não apenas seus sucessos, mas seus equívocos, tanto do passado como recentes. A recorrência à contribuição de outras áreas do conhecimento faz-se cada vez mais presente, sem que, com isso, distancie-se do foco da arquitetura; pelo contrário, estabelecendo-se, entre as diversas áreas, um dinâmico diálogo. São investigações que revelam a ampliação do campo da arquitetura no sentido de sua abrangência e complexidade, conseqüentemente, do papel social do arquiteto.

Os textos dos professores Luis Antonio Jorge e José Forjaz, os quais integram a seção Depoimentos, abrem com muita pertinência a discussão que se faz necessária e urgente no universo arquitetônico, especialmente em países em que ainda convivem grandes contrastes sociais. Fruto de um convênio firmado entre a Faculdade de Arquitetura e Urbanismo da Universidade de São Paulo e a Faculdade de Arquitectura e Planeamento Físico da Universidade Eduardo Mondlane, em Maputo, Moçambique, e com a colaboração do Museu da Casa Brasileira foram realizadas exposições e palestras do arquiteto José Forjaz, cuja obra é uma resposta das mais criativas aos problemas de sua realidade. Consciente da responsabilidade do arquiteto diante dos problemas urbanos e crítico contumaz do exibicionismo e do desperdício que assola a produção atual, Forjaz defende, em seu texto, a necessidade de descolarmo-nos dos atraentes apelos veiculados pela mídia arquitetônica internacional e de concentrarmo-nos em nossos problemas, buscando resolvê-los dentro de nossas carências e segundo nossas reais possibilidades, sem artimanhas, porém com muita criatividade. A importância dos estudos comparativos entre os países de colonização portuguesa, precisamente exposta na apresentação do professor Luis Antonio, abre a perspectiva para muitas possibilidades de pesquisa, em um campo praticamente inexplorado.

No âmbito da revisão historiográfica que tem caracterizado as investigações das últimas décadas, Anat Falbel se propõe a debater a construção da narrativa da moderna arquitetura brasileira. Estruturado em três abordagens espaciais, "Espaço e Interações na Historiografia da Arquitetura Moderna Brasileira", inicialmente, apresenta o contexto a partir do qual essa construção foi desenvolvida, tomando como seu principal propositor o arquiteto Lucio Costa e sua posição perante a efervescência cultural da década de 1930 marcada, segundo a autora, pelo viés autoritário, nacionalista e populista do governo Vargas. A segunda questão lançada refere-se à geografia cultural, na qual é discutida a compreensão de Costa sobre o conceito de história, sobre a construção de uma identidade nacional, a partir das relações por ele estabelecidas entre a arquitetura colonial e arquitetura moderna, e o confronto com as idéias de seus contemporâneos, os historiadores americanos George Kubler e Robert Chester Smith. Por fim, a última questão analisa a noção de diálogo cultural, segundo as teorias de Georg Simmel e Martin Buber, cujo conceito do espaço in-between ressalta a contribuição do diálogo para a absorção das dissonâncias entre os distintos pontos de vista. 
O artigo de Rafael Antonio Cunha Perrone, "A citação como referência e a referência como citação", traz à tona um tema difícil de ser trabalhado pelos arquitetos, revelando uma saudável mudança na compreensão das referências à criação arquitetônica. A partir da analogia com as citações em textos acadêmicos, o autor faz a diacronia das citações no âmbito da criação arquitetônica, recuperando-as quando utilizadas de forma direta ou indireta, e analisando sua contribuição para o desenvolvimento das idéias em arquitetura.

A análise semiótica de Lucrécia D’Alessio Ferrara, intitulada "Desenho industrial: Da transmissão à tradução", recupera o desenvolvimento do campo do design diante dos desafios enfrentados quando de seu surgimento no século 19 e compara-os aos de hoje, quando se verifica uma outra lógica de produção industrial, baseada na substituição do valor de troca pelo valor de acumulação consumista. Este artigo contribui, para além das indagações nele lançadas, a evidenciar a retomada da semiótica, tão presente nas discussões arquitetônicas dos anos 70 e 80, novamente perscrutada pelas investigações acadêmicas mais recentes, constatando, talvez, sua permanência durante esses anos, mas sem dúvida uma nova ênfase que lhe vem sendo atribuída com a criação do curso de design na FAUUSP e de muitos outros mais específicos pelo país afora.

Muitas têm sido as investigações sobre a produção da arquitetura e do urbanismo e seu papel na conformação das cidades, analisando problemas de escalas e tempos distintos, bem como de complexidades e temas variados, cuja reflexão contribui para a compreensão de problemas contemporâneos. No primeiro, "Sobre o vazio: As esquinas Cerdà, os bulevares parisienses e as squares londrinenses", Vanessa Maas traz reflexões sobre os espaços urbanos decorrentes do projeto arquitetônico, atendo-se aos três exemplos anunciados no título. Os vazios, segundo a autora, são decisivos para a compreensão do espaço construído, uma vez que reforçam a morfologia urbana, facilitando, assim, sua legibilidade. A partir de três contextos distintos, a partir da análise isolada e comparada dos três casos, cujo único ponto comum é a intenção projetual, Maas estabelece duas categorias de observação: pequena ou média escala, e grande escala.

Com o texto "Informalidade nas sociedades de elite da América Latina", Csaba Deák coloca em discussão as práticas da informalidade disseminadas na cultura latinoamericana, especialmente nas elites sociais, seja na apropriação dos espaços urbanos, seja na produção econômica. Sendo as causas identificadas como as próprias peculiaridades estruturais dessas sociedades de elite, a possibilidade de mudança é vislumbrada pelo autor no movimento de unificação da América Latina.

A habitação de interesse social permanece como campo profícuo de investigação acadêmica, infelizmente na mesma proporção do aumento de sua complexidade enquanto política pública. Em "Das fronteiras do conjunto ao conjunto das fronteiras", Guilherme Moreira Petrella analisa o modelo recorrente de projeto para a habitação de interesse social baseado no formato de conjuntos habitacionais. A partir do estudo de casos de diferentes contextos históricos e iniciativas, como Cecap Zezinho Magalhães Prado, Cohab Cidade Tiradentes Santa Etelvina, Mutirão autogerido Copromo, CDHU Iguatemi, Parque do Gato e Cingapura Zaki Narchi, o autor questiona a idéia de conjunto habitacional como proposta de moradia e constituição de cidade.

Em "A constituição do habitus na produção do hábitat", Paulo Romano Reschilian investiga, a partir das idéias de Pierre Bourdieu, o modo de vida do morador de assentamentos precários, buscando identificar a existência de uma cultura que não se condiciona, a princípio, pelos parâmetros da modernidade e revela hábitos de morar e inserir-se no ambiente, de forma igualmente precária. Apoiado em uma metodologia qualitativa, o autor levantou, além dos indicativos socioeconômicos, objetivos e quantitativos, os indicativos subjetivos relacionados ao campo da cultura, de modo a identificar o modo de vida dos moradores de Nova Tatetuba, em São José dos Campos, e sua resistência à transferência para conjuntos habitacionais oferecidos pelo poder público.

No âmbito do planejamento urbano, Cilene Gomes e Marcia Sotto-Maior Bayer analisam em "Interações entre aeroporto, cidade e região: Desafios para uma ação a respeito do caso de São José dos Campos (SP)", as relações entre o aeroporto e o desenvolvimento da cidade de São José dos Campos, refletindo sobre a complexidade da localização desses equipamentos, tendo em vista seu papel enquanto elemento estruturador do desenvolvimento urbano, tanto em escala local como regional. Em um momento de ampla expansão nacional desse meio de transporte e da inadequação dos equipamentos existentes à crescente demanda, a investigação sobre suas interações com o desenvolvimento de cidades e regiões, no contexto das distintas formações territoriais brasileiras, bem como a sugestão de uso de sistemas de monitoramento e gestão e instrumentos de planejamento revelam a sintonia das pesquisas acadêmicas aos problemas atuais.

Completa o quadro das reflexões aqui apresentadas o artigo "Os edifícios antigos de arquitetura corrente em 
centros históricos no contexto do patrimônio cultural: Especificidades e condicionantes para projetos de intervenção arquitetônica", de Fernanda Corrêa Giacomini e Rui Humberto Costa de Fernandes Póvoas, trazendo à discussão problemas relativos à expansão do campo da preservação, especialmente aqueles que afetam a maioria dos centros urbanos constituídos. A arquitetura corrente, entendida pelos autores como obras anônimas, sem singularidade e sem significado artístico, passou a ser incluída entre os bens de interesse histórico, impondo-Ihe a condição de patrimônio cultural a exigir de qualquer intervenção construtiva a observância aos pressupostos teóricos da restauração. Condição essa que os autores questionam sob a alegação de essas obras não terem o mesmo valor arquitetônico daquelas de autor ou de significativa expressão artística, exigindo, portanto, uma adaptação dos pressupostos caso a caso.

Aguçam o debate lançado por Giacomini e Póvoas as idéias apresentadas por Beatriz Mugayar Kühl, em sua introdução ao registro do "Seminário de Estudos sobre Restauração Arquitetônica: 'Técnicas Analíticas e de Diagnóstico de Bens Culturais: Experiências Italianas Recentes'" por ela organizado, publicado em seguida na seção Eventos. Esse seminário é parte do convênio firmado entre a Faculdade de Arquitetura da Sapienza com a FAUUSP, contando com sistemática e rigorosa apresentação dos resultados na revista Pós, contribuindo fortemente para a reflexão sobre as questões da preservação, que nesta edição teve a participação do pesquisador italiano Nicola Santopuoli, cuja palestra "A contribuição da ciência para a restauração dos bens monumentais" completa o relato. Em sua apresentação, Kühl ressalta a importância de debater-se os aspectos teórico-metodológicos e técnico-operacionais da restauração, no sentido de promover-se maior consciência sobre os problemas envolvidos e fornecer elementos de reflexão para intervir de modo responsável no meio construído, com clareza e coerência de critérios, respeitando a configuração, a constituição física e as várias estratificações que a obra (ou o conjunto de obras) adquiriu ao longo do tempo.

O relato de Anne Marie Sumner, "Idéia de constituição de Um Escritório Experimental de Projetos", inaugura, na seção Núcleos, Laboratórios, Serviços de Apoios Didáticos, conforme anunciado na edição anterior, a abertura para a divulgação também de experiências externas à comunidade FAUUSP. O desejo de compartilhar esforços para o aprimoramento da arquitetura e a constatação de várias tentativas nesse sentido, levou-nos a acolher trabalhos que possam contribuir para esse enriquecimento. A proposta de um escritório experimental é antiga e recorrente, o que nos levou a considerar sua pertinência para a atualização do debate, e o material reunido por Anne Marie traz depoimentos e informações preciosas, cujo registro e divulgação entendemos como um compromisso com a cultura arquitetônica. A recuperação de algumas tentativas de aproximação da prática profissional à academia levadas à frente por docentes e projetistas, alguns já falecidos, constitui importante documento histórico.

Duas resenhas completam o quadro de atualização das investigações científicas no campo da arquitetura, do urbanismo e do design, a que essa revista se propõe: "Desenho universal: Caminhos da acessibilidade no Brasil", por Vilma Villarouco e "Por uma História dos Projetos de Habitação Social", de minha autoria.

Na seção In memoriam, com grande pesar comunicamos a perda de dois colegas, Dario Montesano e Murillo Marx, por intermédio dos textos de Silvio Soares Macedo e Renato Cymbalista, respectivamente.

Por fim, queremos deixar registrada a incrível realização do Fórum do Plano Diretor Participativo da FAUUSP, cujos histórico, proposta e resultados finais serão apresentados na próxima edição. Entretanto, não queremos postergar a congratulação à tal realização, ou melhor, à tamanha conquista. Durante dois dias foi realizada a votação ponto por ponto, emenda a emenda, do resultado do intenso e eficiente trabalho de quase dois anos do Conselho Curador. O Plano Diretor Participativo da FAUUSP, conforme anuncia seu artigo primeiro, "é um instrumento elaborado e aprovado de forma participativa e paritária, entre professores, funcionários e estudantes, que estabelece princípios e diretrizes para regulamentar, estruturar e orientar as intervenções no espaço do conjunto de edifícios da FAUUSP - já pertencentes à Faculdade ou que dela venham a fazer parte - e das respectivas áreas adjacentes sob sua salvaguarda". Uma realização que consagra a participação e o diálogo como meios legítimos de reflexão e amadurecimento para a cultura arquitetônica.

Finalizando, em Comunicados relacionamos teses e dissertações defendidas na FAUUSP no último semestre de 2010.

Boa leitura.

Mônica Junqueira de Camargo
Editora-chefe
junqueira.monica@usp.br
rvposfau@usp.br
( 11)3015-3164

Mônica Junqueira de Camargo

junqueira.monica@usp.br

( 11) 3015-3164 